\title{
Coordinating of O2O Fresh Agricultural Products Supply Chain with Asymmetric Information When Disturbance Occur Online
}

\author{
Leizhou Zhao ${ }^{1}$ \& Qing Zhang ${ }^{1}$ \\ ${ }^{1}$ School of Economics and Management, Nanjing University of Aeronautics and Astronautics, Nanjing, China \\ Correspondence: Leizhou Zhao, School of Economics and Management, Nanjing University of Aeronautics and \\ Astronautics, Nanjing, China. E-mail: zlz7681466@163.com
}

Received: November 10, 2017

Accepted: November 23, 2017 Online Published: November 27, 2017

doi:10.5539/jms.v7n4p132

URL: http://doi.org/10.5539/jms.v7n4p132

\begin{abstract}
With lots of hot money focusing on the field of fresh product, the fresh product e-commerce enterpraises developed rapidly, but quickly declined later. The aim of this paper is to explain the problem form view of supply chain by setting up the model of fresh produce supply chain. The decision model can be obtained including optimal retail price, sales volume and profit of supply chain whether in the condition of centralized decision-making or disperse policy decision. It can draw the conclusion that, in the condition of asymmetric information, price subsidy of the fresh produce $\mathrm{O} 2 \mathrm{O}$ supply chain could promote the profit when online sales volume stay lower. Also, the increase of online sales volume results in the decrease of optimal retail price and subsidy price, and modified Wholesale Price Contract can coordinate the supply chain in disperse policy decision. Finally, the advice for enterpraises and supply chain has been listed.
\end{abstract}

Keywords: information asymmetry, O2O, fresh agricultural products, supply chain coordination

\section{Introduction}

With the increase of disposable income, people begin to pay attention to the improvement of the quality of life, especially the daily requirements of fruits and vegetables and meat products. As e-commerce developing for many years in China, the payment online has been brought into our eyes, especially among the teenagers. What's more, e-commerce business model has stepped into $\mathrm{O} 2 \mathrm{O}$ which means online to offline originally but interaction between online and offline now.

When lots of capital is invested into $\mathrm{O} 2 \mathrm{O}$ field, the last blue ocean of e-commerce is aimed at the fresh agriculture produce $\mathrm{O} 2 \mathrm{O}$ market, including fresh garden stuff, seafood and meat product. The development of $\mathrm{O} 2 \mathrm{O}$ fresh market also provides more choices for residents, and gets rid of the embarrassing situation of many varieties on the surface and few actual choices'.

Because fund battle arose in the $\mathrm{O} 2 \mathrm{O}$ model filed in recent years, the fresh agriculture produce market appears into disorder through the 2016. According to "China e-commerce of fresh agriculture produce development white paper", the number of company, in the fresh agriculture produce field, has been already beyond 4 thousand. Among them, $88 \%$ of enterprises in a slightly worse state, $7 \%$ face huge losses, while only $4 \%$ of the company can maintain a balance of profits and losses.

For the arrival at the $\mathrm{O} 2 \mathrm{O}$ era, it also brings more new problems to e-commerce enterprises and supply chain. Problems of enterprise stragety in different stages and profit model will lead to the closure of enterprises, waste of money, energy and unsustainable supply chain development. From the perspective of fresh agricultural product supply chain, this paper tries to explain the difficulties faced by fresh e-commerce enterprises in the current $\mathrm{O} 2 \mathrm{O}$ fresh market, and throw out some suggestions for improvement.

\section{Literature Review}

Recent literature about fresh agricultural products supply chain mainly focuses on channel service promotion and competition, unexpected events, inventory and order. Wu (2012), considering the time constraint, studied the supply chain coordination mechanism of fresh agricultural product supply chain under unexpected conditions. Also, Wang (2012) finds that the value of fresh products decreased significantly during the transfer process, and through the establishment of an option contract to study the optimal order quantity of retailers in the two stages. Li lin (2015) through the research on decision model of single cycle retailer, in three different modes, expounds 
the relationship between the value of the attenuation coefficient and the inventory cost parameters, the results showing that RFID technology can help to improve the market demand and achieve flexible pricing. Xiong (2015) analyzes the relationship between cold chain facilities and freshness, and the study shows that relational contracts could promote the freshness of fresh products, and proper cold chain facilities subsidies could strengthen the stability of the contract system. Based on the research and study, the fresh fresh agricultural products supply chain can be seen as a function system that since the product has been picked, the suppliers, distributors or other logistics service providers have carried on the preservation, packaging, transportation, processing, and then the retailer will deliver products to consumers, and finally complete the delivery of logistics, capital flow and information flow. By the way, cold chain logistics, the most important link in the supply chain, generally refers to refrigeration, frozen food in the production, storage, transportation, sales, before the consumption of all links in the condition of prescribed low temperature, in order to ensure the quality of food, reduce food loss.

In the study of $\mathrm{O} 2 \mathrm{O}$ model, more scholars mainly focus on service, recommendation and logistics optimizing. Kong dong $(2016,2015)$ interprets the relationships between value, innovation and realization based on case analysis. Meanwhile, with lots of research about $\mathrm{O} 2 \mathrm{O}$ classification system, he compares the $\mathrm{O} 2 \mathrm{O}$ model among e-commerce companies and concludes its characteristic and range of application. Liu (2015) research O2O foodservice industry online comment, and the result indicate that brand value has moderating effect on the relationship between negative comments and usefulness of reviews, which high brand value will reduce the negative effect of negative comments on the usefulness of comments. Xu (2016) mainly studies the supply chain of two channels and finds that there is a competitive relationship between the same products when they are sold in different channels. Dumrongsiri (2014) analyzed the relationship between the overall profit of the dual channel supply chain and the service quality of retailers, and the results showed that retailers can improve the service quality and promote the income of the dual channel supply chain.

As for supply chain coordination and information asymmetry, Cai (2009) takes the relation between channel structure and supply chain decision as the research object, and expounds the application of price discount contract in supply chain coordination. Considering the risk factors of supply chain, Jiang (2015) compares the four models in the wholesale price, retail price and product green degree, based on the revenue sharing contract, analyses coefficient influence on supply chain profit and revenue sharing of product green degree. $\mathrm{Wu}(2015)$, in the case of asymmetric information of cost, he studied how to deal with centralized and decentralized supply chain. Dan (2013) based on the game theory, establishes a game model between the market operators and wholesalers, considering wholesalers completely hidden, partly hidden and share purchase price information three cases, and analyzes the dynamic game process.

In this paper, the influence of time constraint on the profit of fresh agricultural product supply chain is considered in the fresh $\mathrm{O} 2 \mathrm{O}$ model. Secondly, this paper mainly analyses the impact of online price changes on the supply chain profits. Based on the above situation, in the $\mathrm{O} 2 \mathrm{O}$ fresh supply chain of agricultural products in this paper, online disturbance, especially refers the online platform for snatching market share and adopting the price subsidy.

\section{Method and Model}

The supply chain model, in this paper, is composed of suppliers and retailers, as well as a third party $\mathrm{O} 2 \mathrm{O}$ business platform. Among them, fresh agricultural products are sold by supplier to retailers, while the retailer mainly sells them to customers through the offline store and provides consuming experience. At the same time, the third party electronic business platform is mainly responsible for online trading of fresh agricultural products, information feedback, and follow-up logistics, distribution and after-sales service. In order to reflect the loss of fresh agricultural products, perishable characteristics, two parameters are defined, namely freshness parameter $\alpha$ and effective fresh proportion parameter $\beta$. The model is as follows:

$$
\begin{cases}\alpha=1-\frac{t^{3}}{T^{3}} & (0 \leq \mathrm{t} \leq \mathrm{T}) \\ \beta=2-2^{\frac{t}{T}} & (0 \leq \beta \leq 1)\end{cases}
$$

Among them, $\mathrm{T}$ represents the entire effective life cycle of agricultural products, and $\mathrm{t}$ represents the transportation time of fresh agricultural products. Assuming that sales are linear functions of retail prices, constructing the demand function for traditional channels and electronic channels in the $\mathrm{O} 2 \mathrm{O}$ model is as follows: 


$$
\left\{\begin{array}{c}
q_{o}=\alpha\left(\mu a-p_{o}+\theta p_{f}\right) \\
q_{f}=\alpha\left((1-\mu) a-p_{f}+\theta p_{o}\right)
\end{array}\right.
$$

In the model, letter a represents the market size of the supply chain, and $\mu(0<\mu<1)$ represents the proportion of demand for online channels. cs refers to the cost of supplier, and cr refers to the cost of retailer, while $\theta(0<\theta<1)$ refers to inter channel price substitution factor, and $\omega$ refers to wholesale price. Also, there is no replenishment delay in the hypothesis.

In this paper, retailer, as a link between offline sales and online sales, should consider the online and offline specific circumstances to choose its business strategy. In this part, cost information asymmetry would be taken into consideration in the model, which cs is unknown to detailer, and distribution interval is between $\left[\mathrm{c}_{\mathrm{s}^{-}}, \mathrm{c}_{\mathrm{s}}+\right]$. The distribution function of $\mathrm{cs}$ is $\mathrm{G}\left(\mathrm{c}_{\mathrm{s}}\right)$, while probability density function is $\mathrm{g}\left(\mathrm{c}_{\mathrm{s}}\right)$, and it's expectation is $\eta$. Also, function $\mathrm{G}\left(\mathrm{c}_{\mathrm{s}}\right)$ is differentiable and strictly increasing, $\mathrm{G}(0)=0, \overline{\mathrm{G}}\left(\mathrm{c}_{\mathrm{s}}\right)=1-\mathrm{G}\left(\mathrm{c}_{\mathrm{s}}\right)$. Now, supply chain profit function under information asymmetry has been established as follow:

$$
\begin{aligned}
& \left\{\begin{array}{c}
q_{o}=\alpha(\mu a-(1-\theta) p) \\
q_{f}=\alpha((1-\mu) a-(1-\theta) p)
\end{array}\right. \\
& q=q_{o}+q_{f}=1 \alpha(a-2(1-\theta) p) \\
& \Pi(p)=\int_{c_{s}}^{c_{s}} \alpha(a-2(1-\theta) p)\left(p-\frac{c_{r}+c_{s}}{\beta}\right) g\left(c_{s}\right) d c_{s}
\end{aligned}
$$

Supply chain optimal price, online and offline channel sales and supply chain total profit as follows:

$$
\begin{aligned}
& p^{*}=\frac{a}{4(1-\theta)}+\frac{\eta+c_{r}}{2 \beta} \\
& \left\{\begin{array}{l}
q_{o}=\frac{\alpha}{4}\left((4 \mu-1) a-2(1-\theta) \frac{\eta+c_{r}}{\beta}\right) \\
q_{f}=\frac{\alpha}{4}\left((3-4 \mu) a-2(1-\theta) \frac{\eta+c_{r}}{\beta}\right)
\end{array}\right. \\
& \Pi^{*}=\frac{\alpha\left(a-2(1-\theta) \frac{\eta+c_{r}}{\beta}\right)^{2}}{8(1-\theta)}
\end{aligned}
$$

\subsection{Centralized Decision-making with Online Disturbance}

Nowadays in China, more e-commerce platform of fresh produce starts with $\mathrm{O} 2 \mathrm{O}$ model. For instance, although a large number of stores, there is a big difference between the stores in T-mall. As for price, other shops are working hard on price, coupons, price subsidies, implying that price war is a simple way to integrate online and offline. The current online price disturbance is still mainly based on the third party electronic business platform, direct or indirect price subsidies, such as discounts, coupons, and other means.

Assume that " $p$ " is third party platform for online channel unit product price subsidies. Considering the supplier cost information asymmetry, the demand function of the $\mathrm{O} 2 \mathrm{O}$ supply chain is as follows:

$$
\begin{gathered}
\left\{\begin{array}{c}
q_{o}=\alpha\left(\mu a-\left(p-p_{a}\right)+\theta p\right) \\
q_{f}=\alpha\left((1-\mu) a-p+\theta\left(p-p_{a}\right)\right) \\
q=q_{o}+q_{f}=\alpha\left(a-2(1-\theta) p+(1-\theta) p_{a}\right)
\end{array}\right. \\
\prod_{1}(p)=\int_{c_{s}}^{c_{s}}\left(p-p_{a}-\frac{c_{s}+c_{r}}{\beta}\right) \alpha\left(\mu a-(1-\theta) p+p_{a}\right)+\left(p-\frac{c_{s}+c_{r}}{\beta}\right) \alpha\left((1-\mu) a-(1-\theta) p-\theta p_{a}\right) g\left(c_{s}\right) d c_{s} \\
\text { s.t.p, } p_{a} \geq 0
\end{gathered}
$$

When $0<\mu<0.5$, through derivation of $\mathrm{P}$ and $\mathrm{Pa}$, the optimal retail price, price subsidies and total sales and total supply chain profits are as follows: 


$$
\begin{aligned}
& p^{*}=\frac{(1-\mu+\theta \mu) a}{2\left(1-\theta^{2}\right)}+\frac{\eta+c_{r}}{2 \beta} \quad p_{a}^{*}=\frac{(1-2 \mu) a}{2(1+\theta)} \\
& \left\{\begin{array}{c}
q_{o 1} *=\frac{\alpha}{2}\left(\mu a-(1-\theta) \frac{\eta+c_{r}}{\beta}\right) \\
q_{f 1}^{*}=\frac{\alpha}{2}\left((1-\mu) a-(1-\theta) \frac{\eta+c_{r}}{\beta}\right) \\
q_{1}^{*}=q_{o}+q_{f}=\frac{\alpha}{2}\left(a-2(1-\theta) \frac{\eta+c_{r}}{\beta}\right)
\end{array}\right. \\
& \Pi_{1}^{*}=\alpha\left[\frac{a^{2}(1-2 \mu(1-\theta)(1-\mu))}{4\left(1-\theta^{2}\right)}-\frac{\frac{\eta+c_{r}}{\beta}\left(a-(1-\theta) \frac{\eta+c_{r}}{\beta}\right)}{2}\right]
\end{aligned}
$$

Comparison with formula 3, supply chain profit fluctuation is as follow:

$$
\Delta \Pi=\Pi_{1} *-\Pi^{*}=\alpha \frac{a^{2}(1-2 \mu)^{2}}{8(1+\theta)}>0
$$

Theorem 1: when online channel sales are at a low level $(0<\mu<0.5)$, the online subsidy mechanism could increase the $\mathrm{O} 2 \mathrm{O}$ supply chain profits, and optimal price and online subsidies prices are as follow:

$$
p^{*}=\frac{(1-\mu+\theta \mu) a}{2\left(1-\theta^{2}\right)}+\frac{\eta+c_{r}}{2 \beta} \quad p_{a}^{*}=\frac{(1-2 \mu) a}{2(1+\theta)}
$$

Inference 1: When the cost information of supplier in the supply chain is asymmetric, the information asymmetry will not interfere with the price subsidy decision.

\subsection{Decentralized Decision-making}

When roles of supply chain pursue the maximization of their own profit, the profit function of the supply chain is as follows:

$$
\begin{aligned}
& \Pi_{r 2}=\left(p-p_{s}-\frac{\omega+c_{r}}{\beta}\right) \alpha\left(\mu a-(1-\theta) p+p_{s}\right)+\left(p-\frac{\omega+c_{r}}{\beta}\right) \alpha\left((1-\mu) a-(1-\theta) p-\theta p_{s}\right) \\
& \Pi_{s 2}=\int_{c_{s}}^{-} c_{s}^{c_{s}}\left(\frac{\omega-c_{s}}{\beta}\right) \alpha\left(a-2(1-\theta) p+(1-\theta) p_{s}\right) g\left(c_{s}\right) d c_{s}
\end{aligned}
$$

Derivation in sequence, retail prices, subsidies and wholesale prices are as follows:

$$
\begin{aligned}
& p_{2}^{*}=\frac{3 a}{8(1-\theta)}+\frac{a(1-2 \mu)}{2(1+\theta)}+\frac{c_{r}+\eta}{4 \beta} \quad \omega=\frac{a \beta}{4(1-\theta)}+\frac{\eta-c_{r}}{2} \quad p_{a 2}=\frac{(1-2 \mu) a}{2(1+\theta)} \\
& q_{2}{ }^{*}=\alpha\left(\frac{a}{4}-\frac{(1-\theta)\left(c_{r}+\eta\right)}{2 \beta}\right) \\
& \left\{\begin{array}{l}
q_{o l 2}{ }^{*}=\alpha\left(\frac{(4 \mu-1) a}{8}-\frac{(1-\theta)\left(c_{r}+\eta\right)}{4 \beta}\right) \\
q_{f l 2}{ }^{*}=\alpha\left(\frac{(3-4 \mu) a}{8}-\frac{(1-\theta)\left(c_{r}+\eta\right)}{4 \beta}\right)
\end{array}\right.
\end{aligned}
$$

Thus, $p_{2}^{*} \neq p^{*}$, in the decentralized decision-making, the $\mathrm{O} 2 \mathrm{O}$ supply chain of fresh agricultural products cannot achieve the optimal supply chain profit.

\subsection{Coordination with Traditional Wholesale Price Contract}

Traditional wholesale price contract is an almost common contract in fresh produce market, which retailers buy goods at low prices and sell on this basis. Considering subsidy from e-commerce platform, profit functions of retailer and supplier are as follow, in which sign m means traditional wholesale price contract. 


$$
\begin{aligned}
& \Pi_{r}^{m}=\left(p-p_{s}-\frac{\omega+c_{r}}{\beta}\right) \alpha\left(\mu a-(1-\theta) p+p_{a}\right)+\left(p-\frac{\omega+c_{r}}{\beta}\right) \alpha\left((1-\mu) a-(1-\theta) p-\theta p_{a}\right) \\
& \Pi_{s}^{m}=\int_{c_{s}}^{c_{s}}\left(\frac{\omega-c_{s}}{\beta}\right) \alpha\left(a-2(1-\theta) p+(1-\theta) p_{a}\right) g\left(c_{s}\right) d c_{s}
\end{aligned}
$$

Because retailer sells on the basis of wholesale prices, the relationship between price and wholesale price can be

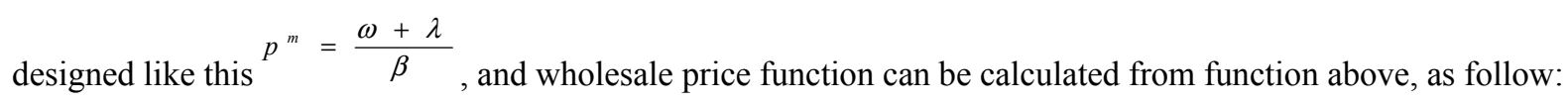

$$
\omega^{m}=\frac{\beta a}{4(1-\theta)}+\frac{\eta}{2}+\frac{\beta p_{a}}{4}-\frac{\lambda}{2}
$$

Through computing form function (10), parameters are as follow:

$$
\lambda^{m}=\frac{a \beta(1-\mu+\theta \mu)}{2\left(1-\theta^{2}\right)}+\frac{c_{r}-\eta}{2} \quad \omega^{m}=\frac{a \beta}{8(1-\theta)}+\frac{3 \eta-c_{r}}{4} \quad \mathrm{p}^{\mathrm{m}}=\frac{\eta+c_{r}}{4 \beta}+\frac{a(4 \mu \theta-4 \mu+\theta+5)}{8\left(1-\theta^{2}\right)}
$$

And The number of channel sales is as follows:

$$
\begin{aligned}
& \left\{\begin{array}{l}
q_{o 1}{ }^{m}=\frac{\alpha}{8}\left(a(4 \mu-1)-2(1-\theta) \frac{\eta+c_{r}}{\beta}\right) \\
q_{f 1}{ }^{m}=\frac{\alpha}{8}\left((3-4 \mu) a-2(1-\theta) \frac{\eta+c_{r}}{\beta}\right)
\end{array}\right. \\
& q^{m}=\frac{\alpha}{4}\left(a-\frac{2(1-\theta)\left(\eta+c_{r}\right)}{\beta}\right)
\end{aligned}
$$

Also, the retailer and supplier profit function is as follows:

$$
\begin{aligned}
& \Pi_{r}{ }^{m}=\alpha\left[\frac{a^{2}\left((1-\theta)\left(8 \mu^{2}-8 \mu\right)+3-\theta\right)}{16\left(1-\theta^{2}\right)}-\frac{a\left(c_{r}+\eta\right)}{4 \beta}+\frac{(1-\theta)\left(c_{r}+\eta\right)^{2}}{4 \beta^{2}}\right] \\
& \Pi_{s}{ }^{m}=\alpha\left[\frac{a^{2}}{32(1-\theta)}-\frac{a\left(c_{r}+\eta\right)}{8 \beta}+\frac{(1-\theta)\left(c_{r}+\eta\right)^{2}}{8 \beta^{2}}\right]
\end{aligned}
$$

Supply chain profit differential between centralized decision-making and decentralized decision-making with traditional wholesale price contract is as follow:

$$
\Delta \Pi=\Pi_{s}{ }^{m}+\Pi_{r}{ }^{m}-\Pi_{1}^{*}=\frac{-\alpha}{32(1-\theta) \beta^{2}}[a \beta-2(1-\theta) c]^{2}<0
$$

Theorem 2: when price disruption occurs online, traditional wholesale price contract can't realize the coordination of the fresh produce $\mathrm{O} 2 \mathrm{O}$ supply chain.

\subsection{Improved Wholesale Price Contract Coordinate the O2O Supply Chain}

Although the "bilateral effect" is main reason that, under decentralized decision-making, the O2O supply chain cannot achieve the best overall profit of the supply chain. However, the supply chain can promote the profit of the members in the supply chain through effective contract. In the current retail giants dominate the $\mathrm{O} 2 \mathrm{O}$ supply chain of fresh agricultural products, this paper uses improved wholesale price contract. In the contract, the supplier promises to give the retailer a lower wholesale price before the sales season, while paying a certain service fee, and the retailer increases the price on the basis of wholesale price. In the formula, $\omega$ means wholesale price, $C$ means service fee, and $\lambda$ means increased price $(\lambda>0$, meaning markup sale; $\lambda<0$, meaning discount sale). The contents of the contract are as follows (symbol "T" represents improved wholesale price contract):

The retailer's unified pricing and online order subsidies are as follows: 


$$
p^{T}=\frac{\omega+\lambda}{\beta} \quad p_{\mathrm{a}}{ }^{\mathrm{T}}=p_{\mathrm{a}}{ }^{*}=\frac{(1-2 \mu) a}{2(1+\theta)}
$$

And the profit function of retailers and suppliers is as follows:

$$
\begin{aligned}
& \Pi_{r}^{T}=\left(p-p_{a}-\frac{\omega+c_{r}}{\beta}\right) \alpha\left(\mu a-(1-\theta) p+p_{a}\right)+\left(p-\frac{\omega+c_{r}}{\beta}\right) \alpha\left((1-\mu) a-(1-\theta) p-\theta p_{a}\right)+T \\
& \Pi_{s}^{T}=\int_{c_{s}}^{c_{s}}\left(\frac{\omega-c_{s}}{\beta}\right) \alpha\left(a-2(1-\theta) p+(1-\theta) p_{a}\right) g\left(c_{s}\right) d c_{s}-T
\end{aligned}
$$

Solve the formula 10 and get the wholesale price function of $\lambda$ and $\mathrm{paC}$ :

$$
\omega^{T}=\frac{\beta a}{4(1-\theta)}+\frac{c_{r}}{2}+\frac{\beta p_{a}}{4}-\frac{\lambda}{2}
$$

Because $p^{T}=p^{*}$, then get $\lambda^{T}=\frac{a(1-2 \mu) \beta}{4(1+\theta)}+c_{r}$, coordinating the supply chain, decision parameters are as follow:

$$
\begin{aligned}
& \omega^{T}=\frac{\beta a}{4(1-\theta)}+\frac{\eta-c_{r}}{2} \quad p^{T^{*}}=\frac{(1-\mu+\theta \mu) a}{2\left(1-\theta^{2}\right)}+\frac{\eta+c_{r}}{2 \beta} \\
& \left\{\begin{array}{l}
q_{o l}{ }^{T} *=\frac{\alpha}{2}\left(\mu a-(1-\theta) \frac{c_{s}+c_{r}}{\beta}\right) \\
q_{f l}{ }^{T} *=\frac{\alpha}{2}\left((1-\mu) a-(1-\theta) \frac{c_{s}+c_{r}}{\beta}\right)
\end{array}\right. \\
& q^{T *}=\frac{\alpha}{2}\left(a-2(1-\theta) \frac{c_{s}+c_{r}}{\beta}\right)
\end{aligned}
$$

The profit functions of retailer and supplier with improved wholesale price contract are as follow:

$$
\Pi_{r}{ }^{T}=\alpha\left[\frac{a^{2}(1-2 \mu)^{2}}{8(1+\theta)}\right]+T \quad \Pi_{s}{ }^{T}=\alpha\left[\frac{\left(a \beta-2(1-\theta)\left(c_{r}+\eta\right)\right)^{2}}{8(1-\theta) \beta^{2}}\right]-\mathrm{T}
$$

To realize the Pareto improvements of roles in supply chain, that is, the profit of retailer and supplier with improved wholesale price contract is no less than that under decentralized decision-making. The range of $\mathrm{C}$ is as follow:

$$
\text { Solving equation: }\left\{\begin{array}{ll}
\Pi_{s}{ }^{T} \geq \Pi_{s}{ }^{m} \\
\Pi_{r}{ }^{T} \geq \Pi_{r}{ }^{m}
\end{array} \text {, then } \begin{array}{l}
T \in\left(T_{1}, T_{2}\right) \\
T_{1}=\frac{\alpha}{16(1-\theta) \beta^{2}}\left[a \beta-2(1-\theta)\left(c_{r}+\eta\right)\right]^{2} \\
T_{2}=\frac{3 \alpha}{32(1-\theta) \beta^{2}}\left[a \beta-2(1-\theta)\left(c_{r}+\eta\right)\right]^{2}
\end{array}\right.
$$

Theorem 3: decentralized decision-making fresh produce $\mathrm{O} 2 \mathrm{O}$ online disturbance can be coordinated by improved wholesale price contract, and the contract parameters are as follows:

$$
\begin{aligned}
& \lambda^{T}=\frac{a(1-2 \mu) \beta}{4(1+\theta)}+c_{r}, \mathrm{~T}_{1}, \mathrm{~T}_{2} \text { are stated above. } \\
& T \in\left(T_{1}, T_{2}\right)
\end{aligned}
$$


Inference 2: Form formula $(16,18)$, it can be shown that, asymmetric information could influence decision-making, leading to an inaccurate decision, because parameter $\eta$ is mathematical expectation which can be gain after the event.

\section{Results and Examples Analysis}

This section mainly through numerical examples and chart analysis to verify the correctness of the above theorems and inferences, the supply chain parameters are assigned, the specific parameters are shown in table 1.

Table 1. Parameters assigning

\begin{tabular}{llllllll}
\hline $\mathrm{a}$ & $\mathrm{Cs}$ & $\mathrm{Cr}$ & $\theta$ & $\mu$ & $\mathrm{t} / \mathrm{T}$ & $\alpha$ & $\beta$ \\
\hline 200 & 5 & 5 & 0.4 & 0.4 & 0.25 & 0.93 & 0.81 \\
\hline
\end{tabular}

After parameters are assigned, the decision parameters can be obtained in table 2 .

Table 2. Basic O2O supply chain decision model

\begin{tabular}{lllll}
\hline $\mathrm{p}^{*}$ & $\mathrm{q}^{*}$ & $\mathrm{q}_{\mathrm{ol}}$ & $\mathrm{q}_{\mathrm{ft}}^{*}$ & $\Pi^{*}$ \\
\hline 89.50 & 86.86 & 24.67 & 62.19 & 6702.85 \\
\hline
\end{tabular}

When $t / T$ is in the range of $(0,1)$, and other parameters assigned as table 1 , the relationship between supply chain profit and time is shown in figure 1.

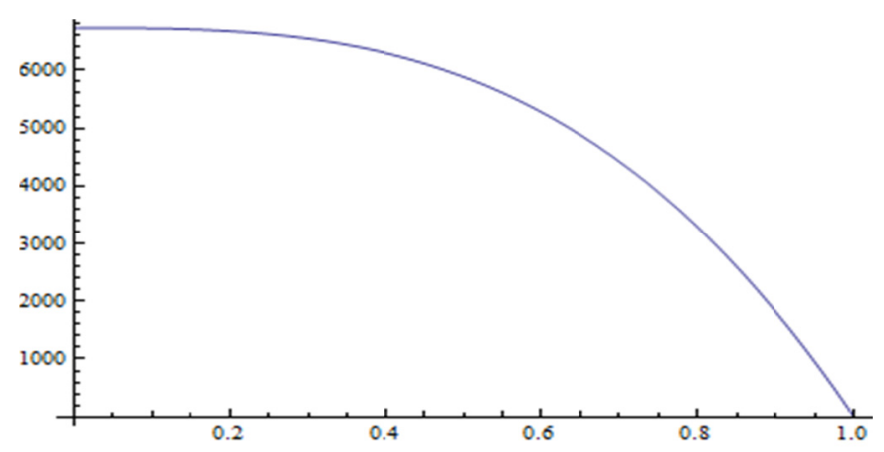

Figure 1. The influence of time on supply chain profit

As shown in Figure 1, the supply chain profit shows a downward trend, and the decline rate is slow first and fast afterwards. It can be understood that when the surface damage of agricultural products appears, it leads to a significant decline in sales and profits. It makes a time inflection point in the fresh products transportation.

With disturbance online, the parameters of $\mathrm{O} 2 \mathrm{O}$ supply chain under centralized decision making and decentralized decision-making are shown in Table 2 and table 3.

Table 3. O2O supply chain centralized decision-making with disturbance online

\begin{tabular}{lllllll}
\hline $\mathrm{p}_{1}{ }^{*}$ & $\mathrm{p}_{\mathrm{a}}$ & $\mathrm{q}_{1}{ }^{*}$ & $\mathrm{q}_{\mathrm{ol}}{ }^{*}$ & $\mathrm{q}_{\mathrm{ft}}{ }^{*}$ & $\Pi_{1} *$ & $\Delta \Pi$ \\
\hline 96.64 & 14.29 & 86.86 & 34.05 & 52.81 & 6836.85 & 134 \\
\hline
\end{tabular}

Table 4. O2O supply chain decentralized decision-making with disturbance online

\begin{tabular}{llllllll}
\hline $\mathrm{p}_{2}{ }^{*}$ & $\mathrm{p}_{\mathrm{a}}$ & $\mathrm{q}_{\mathrm{ol} 2} *$ & $\mathrm{q}_{\mathrm{fl} 2}{ }^{*}$ & $\omega_{2}$ & $\Pi_{\mathrm{s} 2} *$ & $\Pi_{\mathrm{r} 2} *$ & $\Pi_{2}{ }^{*}$ \\
\hline 142.37 & 14.29 & 12.34 & 31.10 & 67.58 & 2730.75 & 1752.44 & 4483.19 \\
\hline
\end{tabular}


Also, $\pi$ represents profit of basic supply chain without online disturbance, while $\pi 1$ represents profit of centralized decision-making supply chain with online disturbance, and $\pi 2$ represents profit of decentralized decision-making supply chain with online disturbance. Parameter $\pi \mathrm{T}$ represents profit of improved wholesale price contract, and $\pi \mathrm{m}$ represents profit of traditional wholesale contract.

What's more, the figures have been drawn to describe the relationships in the supply chain. Among them, the variation of the profit of fresh agricultural product supply chain with the increase of online share on different conditions has been shown in figure 2. Figure 3 has shown variation in the price of agricultural products and the price of online subsidies with the online share changing. Figure 4 has shown that improved wholesale price contract can achieve the Pareto improvement.

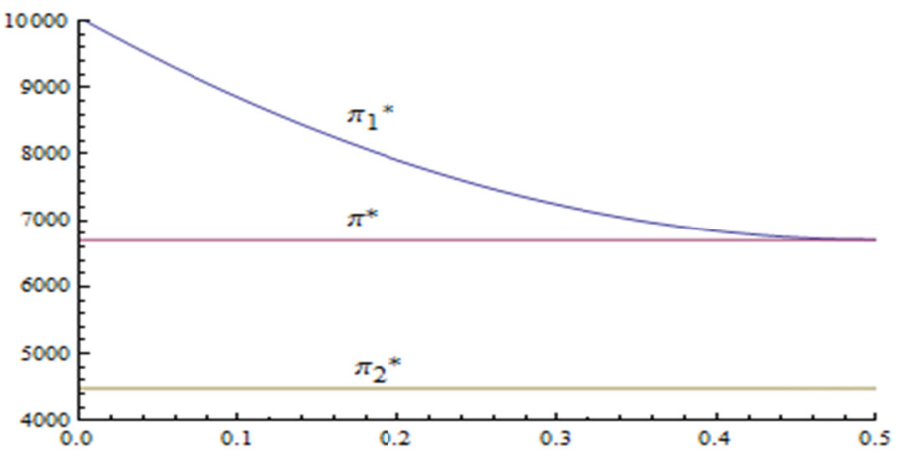

Figure 2. Comparison of supply chain profit

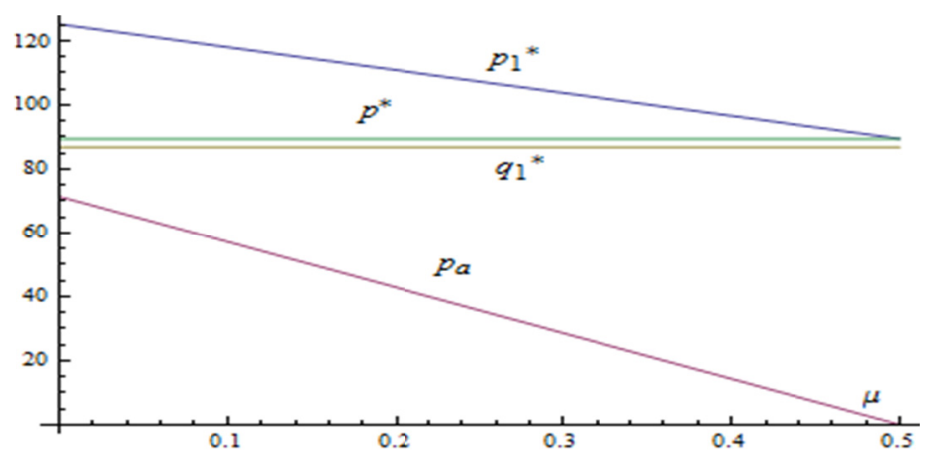

Figure 3. Comparison of price subsidy and retail price in supply chain

Form figure 2, it can be known that when online sale share is at a certain level, supply chain profit with price subsidy is greater than that without subsidy. Also, decentralized decision-making supply chain owns the lowest profit, making no coordination. But with the increase in online share, Subsidies and non-subsidy supply chains profit tend to be the same. In the figure 3, optimal price and price subsidy tends to decrease with online sale share increase with disturbance online, while optimal sales volume donot change.

After assigning the parameters in the contracts, the traditional wholesale price contract and the improved wholesale price are compared and shown in table 5.

Table 5. Comparison of traditional and improved contracts

\begin{tabular}{lllllll}
\hline $\mathrm{T}_{\mathrm{S}}$ & $\Pi_{\mathrm{s}}^{\mathrm{m}}$ & $\Pi_{\mathrm{r}}^{\mathrm{m}}$ & $\Pi_{\mathrm{s}}^{\mathrm{T}}$ & $\Pi_{\mathrm{r}}^{\mathrm{T}}$ & $\Pi^{\mathrm{T}}$ & $\Pi^{*}$ \\
\hline 2700.0 & 1675.6 & 3486.4 & 4002.9 & 2834.0 & 6836.9 & 6836.9 \\
2800.0 & 1675.6 & 3486.4 & 3902.9 & 2934.0 & 6836.9 & 6836.9 \\
3000.0 & 1675.6 & 3486.4 & 3702.9 & 3134.0 & 6836.9 & 6836.9 \\
3352.0 & 1675.6 & 3486.4 & 3350.9 & 3486.0 & 6836.9 & 6836.9 \\
3600.0 & 1675.6 & 3486.4 & 3102.9 & 3734.0 & 6836.9 & 6836.9 \\
3900.0 & 1675.6 & 3486.4 & 2802.9 & 4034.0 & 6836.9 & 6836.9 \\
4200.0 & 1675.6 & 3486.4 & 2502.9 & 4334.0 & 6836.9 & 6836.9 \\
4500.0 & 1675.6 & 3486.4 & 2202.9 & 4634.0 & 6836.9 & 6836.9 \\
\hline
\end{tabular}




\begin{tabular}{lllllll}
\hline 4800.0 & 1675.6 & 3486.4 & 1902.9 & 4934.0 & 6836.9 & 6836.9 \\
5000.0 & 1675.6 & 3486.4 & 1702.9 & 5134.0 & 6836.9 & 6836.9 \\
5027.0 & 1675.6 & 3486.4 & 1675.9 & 5161.0 & 6836.9 & 6836.9 \\
5100.0 & 1675.6 & 3486.4 & 1602.9 & 5234.0 & 6836.9 & 6836.9 \\
5200.0 & 1675.6 & 3486.4 & 1502.9 & 5334.0 & 6836.9 & 6836.9 \\
\hline
\end{tabular}

Also, the change of the profit function and the direction of the parties under the two contracts with the transfer payment is shown in figure 4 .

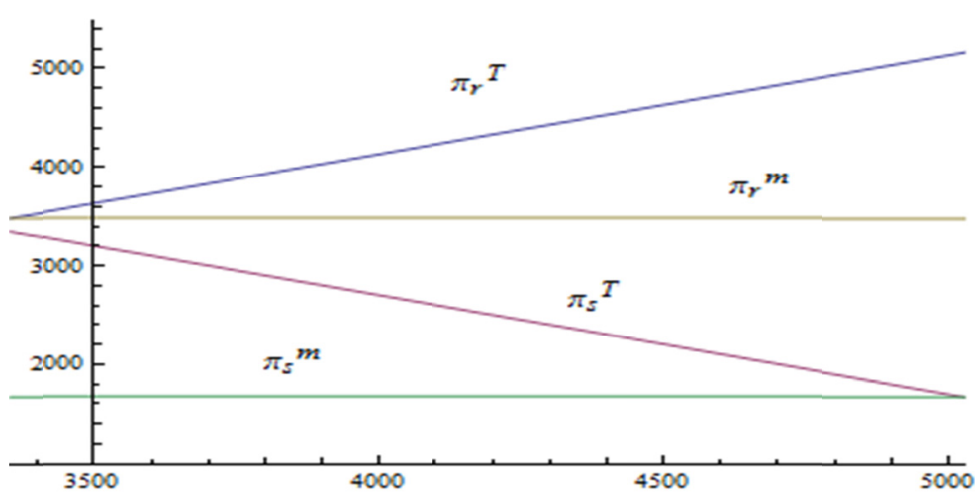

Figure 4. Profit comparison among supply chain members

As we can see in the figure 4, when service fee provided by supplier varies in the certain range, improved wholesale price contract can achieve the Pareto improvement, leaving the coordination to the fresh produce $\mathrm{O} 2 \mathrm{O}$ supply chain.

\section{Conclusion}

As investors become more rational, many e-commerce giants have already changed from blind investment into promoting quality services and a cheap dual track model. Although the subsidy mechanism can help online retailers quickly snatch market resources, however, it has certain limitations and preconditions.

In this paper, fresh produce $\mathrm{O} 2 \mathrm{O}$ supply chain has been established to research supply chain coordination with online price subsidy and information asymmetry. Though computing, the optimal price, price subsidy, total sale volume and optimal supply chain profit can be obtained. The conclusions are as follows.

- First of all, the key factor is still the time of fresh products transportation, directly affects the supply chain's profit level; O2O supply chain facing the online price disturbance, online share in the low level, the existence of subsidies can improve the profit of the supply chain can be regarded as interests of e-commerce company output to the $\mathrm{O} 2 \mathrm{O}$ supply chain. When the online market is in a small scale, the subsidy mechanism can attract customers more quickly and expand the market size. But with the increase of online share, the e-commerce company can cancel the subsidy for the effect reducing.

- Secondly, although the cost of asymmetric information does not interfere with online subsidy mechanism, but it directly affects the profit of the supply chain and the implementation of the overall decision-making, especially in the contract account transfer payment situation, directly affect the formulation and implementation of the contract.

- Finally, when the $\mathrm{O} 2 \mathrm{O}$ supply chain of fresh agricultural products is decentralized and compared with the traditional wholesale price contract, the improved wholesale price contract can coordinate the supply chain of fresh agricultural products and realize the improvement of Pareto.

\section{Discussion and Suggestion}

- Form the conclusion and examples analysis above, it indicates that supply chain profit does not decline linearly with time, but also in line with real life. When you see the surface breakdown of fresh products, that is, the time inflection point in Figure 1, you certainly won't buy it. From this conclusion, e-commerce companies should know that the golden period of fresh products is before the inflection point. So, fresh produce supply chain should focus on the improvement of logistics system, the development of cold chain logistics to shorten the transport time or delay inflection point.

- Fresh e-commerce enterprises should pay attention to online sales share when they subsidize fresh agricultural products online. When online share tends to be the same as offline share, the subsidy should be 
cancelled in time, because the effect of subsidy is very weak and even negligible. This also explains why it is easy to face losses and bankruptcy when the e-commerce enterprises blindly smashing money subsidies for online prices, indicating that the subsidy mechanism is more suitable for the first half of the investment. As for how to operate behind the enterprise, we need more rigorous reasoning, and this paper does not discuss.

- The premise of this method, solving problem of cost information asymmetry, is to know the partial information of the cost, such as the distribution interval and the density function. If the information is completely asymmetric, this method is not applicable.

- This paper uses the improved wholesale price contract because it is easy to implement, and also can achieve the purpose and effect of the contract. But contracts are not unique, and there are many kinds of contracts that can achieve the same effect.

\section{References}

Cai, G., Zhang, Z. G., \& Zhang, M. (2009). Game theoretical perspectives on dual-channel supply chain competition with price discounts and pricing schemes. International Journal of Production Economics, 117(1), 80-96. https://doi.org/10.1016/j.ijpe.2008.08.053

Dan, B., Ding, S., \& Fu, H. Y. (2013). Fresh supply chain coordination by wholesale market in sale place under information asymmetry. Chinese Journal of Management Sciences, 16(10), 40-50.

Dumrongsiri, A., Fan, M., \& Jain, A. et al. (2008). A supply chain model with direct and retail channels. European Journal of Operational Research, 187(3), 691-718. https://doi.org/10.1016/j.ejor.2006.05.044

Jiang, S. Y., \& Li, S. C. (2015). Green supply chain game model and revenue sharing contract with product green degree. Chinese Journal of Management Science, 23(6), 169-176. https://doi.org/10.16381/j.cnki.issn1003-207x.2015.06.022

Kong, D., Zuo, M. Y., \& Sun, K. (2015). Building O2O Model Taxonomic System: A Multi-Case Study. Chinese Journal of Management, 12(11), 1588-1597.

Kong, D., Zuo, M. Y., \& Sun, K. (2016). Elements and their relations of "door-to-door" O2O model: an exploratory study. Management Review, Chinese Journal of Business Review, 28(12), 244-257. https://doi.org/10.14120/j.cnki.cn11-5057/f.2016.12.021

Li, L., \& Fan, T. J. (2015). Comparison and analysis on pricing policies for fresh agricultural produce supply chain with dominant retailer. Chinese Journal of Management Science, 23(12), 113-123. https://doi.org/10.16381/j.cnki.issn1003-207x.2015.12.014

Liu, W., \& Xu, P. T. (2016). A Study on influence factors of the helpfulness of online reviews in O2O of restaurant industry—based on Tobit model. Chinese Journal of Management Science, 24(5), 168-176. https://doi.org/ 10.16381/j.cnki.issn1003-207x.2016.05.019

Wang, J., \& Chen, X. (2012). Fresh produce retailer's optimal options contracts procurement decision research with circulation wastage. Systems Engineering - Theory \& Practice, 32(7), 1408-1414.

Wu, Z. H., Chen, H., \& Liang, C. L. (2015). Supply chain disruptions coordination model of fresh agricultural products under time constrains with asymmetric information. Chinese Journal of Management Science, 23(6), 126-134. https://doi.org/ 10.16381/j.cnki.issn1003-207x.2015.06.016

Wu, Z., Chen, H., \& Zhao, Q. (2012). Supply chain coordination with demand and purchase cost of retailers disruptions. Chinese Journal of Management Science, 20(6), 110-117. https://doi.org/10.16381/j.cnki.issn1003-207x.2012.06.014

Xiong, F., Peng, J., \& Jin, P. (2015). The impact of relational contracts stability about fresh agricultural product supply chain study: from the view of cold chain facilities subsidy mode. Chinese Journal of Management Science, 23(8), 102-111. https://doi.org/ 10.16381/j.cnki.issn1003-207x.2015.08.012

Xu, G., Dan, B., \& Zhang, X. et al. (2014). Coordinating a dual-channel supply chain with risk-averse under a two-way revenue sharing contract. International Journal of Production Economics, 147(1), 171-179. https://doi.org/10.1016/j.ijpe.2013.09.012

\section{Copyrights}

Copyright for this article is retained by the author(s), with first publication rights granted to the journal.

This is an open-access article distributed under the terms and conditions of the Creative Commons Attribution license (http://creativecommons.org/licenses/by/4.0/). 